\title{
Perceptual dependence: Evidence for an internal threshold*
}

\author{
JONATHAN BARON \\ Ic.Master Lniversity, Hamilton, Ontario, Canada
}

\begin{abstract}
Ss were asked to make two forced-choice discriminations on each trial: in Experiment $I$, they had to tell on which side of the display a latter pair appeared and whether or not its members were identical; in Experiment II, to say where the pair appeared and whether it consisted of Xs or Os; in Experiment III, to say where a letter appeared and whather it rhymed with E; and in Experiment IV, to say whether a letter pair was presented and whether it was a word. In Experiment III, and for some Ss in Experiment I, the second discrimination was dependent on the first; that is, when the $S$ was wrong on the first. he performed at chance level on the second. In Experiment IV, when Ss indicated that nothing was presented (with confidence), they performed at chance level on the recognition task; thus, recognition was dependent upon some information about the detection task. It is argued that perceptual dependence implies that a threshold state. a state in which the $S$ has no information, exists for the dependent discrimination. One explanation of dependence assumes mediation of the dependent discrimination by a processing stage which succeeds stages mediating the other task.
\end{abstract}

Disputes about the sources of errors in discrimination tasks often involve the question of whether there is ever a state of the $S$ such that no information can be transmitted about the discrimination in question. Such a state has been called an internal threshold (Krantz, 1969). since equivalent conditions of physical stimulation can also lead to $S$ states in which information can be transmitted. Evidence from the form of ROC curves (Green \& Swets, 1966) suggests that no internal threshold exists for a great variety of discriminations. Krantz (1969), however, has pointed out that the form of ROC curves may be influenced by the consistency with which Ss map internal states into responses, and inconsistency in such mapping could lead to spurious rejection of threshold models on the basis of ROC curves.

Krantz (1969) has shown that one way to demonstrate the existence of an internal threshold in a detection task is to show that there is a lower bound for the posterior probability of a signal, given a "no-signal" response, as S's criterion becomes lower. That is, as $\mathbf{S}$ becomes more and more careful not to make this response unless he is "really sure" a signal was not present, the signal will still in fact be present on some proportion of such trials. If the $S$ can never be sure a signal was not present, this must be because the sensory state corresponding to the lowest likelihood of the signal sometimes occurred even when the signal was presented. Krantz and Brumer (1972) have obtained evidence of the existence of such an internal threshold state for visual detection.

*David H. Krantz has contributed substantially to the development of the ideas in this paper. although he does not necessarily approve of their present form of presentation. Irwin Pollack's considerate editorial handling is much appreciated. He. Saul Stermberg. two anonymous referees, and Corinne Day also made a number of very helpful comments. Financial support was provided by a grant from the National Research Council of Canada.
Another way to demonstrate the existence of an internal threshold state is to select in some way those trials in which the $S$ is in that state with respect to a discrimination (not necessarily a detection task). Direct observation of the S's brain might serve this purpose. But an easier way, demonstrated here, is to give the $\mathrm{S}$ another discrimination to make on each trial using the same stimuli as the discrimination of interest. For example, $\mathrm{S}$ may be asked to report both the position and identity of a visual stimulus. Poor performance, i.e., being wrong, on the first discrimination might select those trials on which the $S$ is in a guessing state with respect to the second. Thus, assuming that both the discriminations are performed above the chance level of success, overall, an internal threshold would be indicated if the conditional probability of a correct response on the second discrimination, given an incorrect response on the first, were at the chance level. In such a situation, we might want to say that being able to make the second discrimination above chance was dependent upon being right on the first. Thus, we shall call such a model perceptual dependence (in contrast to the notions of perceptual independence and correlation described by Garner and Morton, 1969).

In considering the general significance of findings of perceptual dependence, let us designate the dependent task. e.g.. the identity judgment mentioned above, as Task $D$ and the other task as Task C. (The order of $C$ and $D$ in the alphabet may serve as a mnemonic for the direction of dependence.) With respect to each task, the $S$ may be in one of three states on each trial: (1) he may have no information at all, and be forced to guess: (2) he may have some information, enough to guess correctly more often than chance, but not enough to respond with absolute certainty: or (3) he may have enough to respond with absolute certainty. Let us designate the first state as $\bar{C}$ and $\bar{D}$, for the two tasks, respectively: the second as C and $\mathrm{D}$ : and the third as $\mathrm{C}^{*}$ and $\mathrm{D}^{*}$. It is assumed here that States $\mathrm{C}$ and $\mathrm{D}$ may each be 


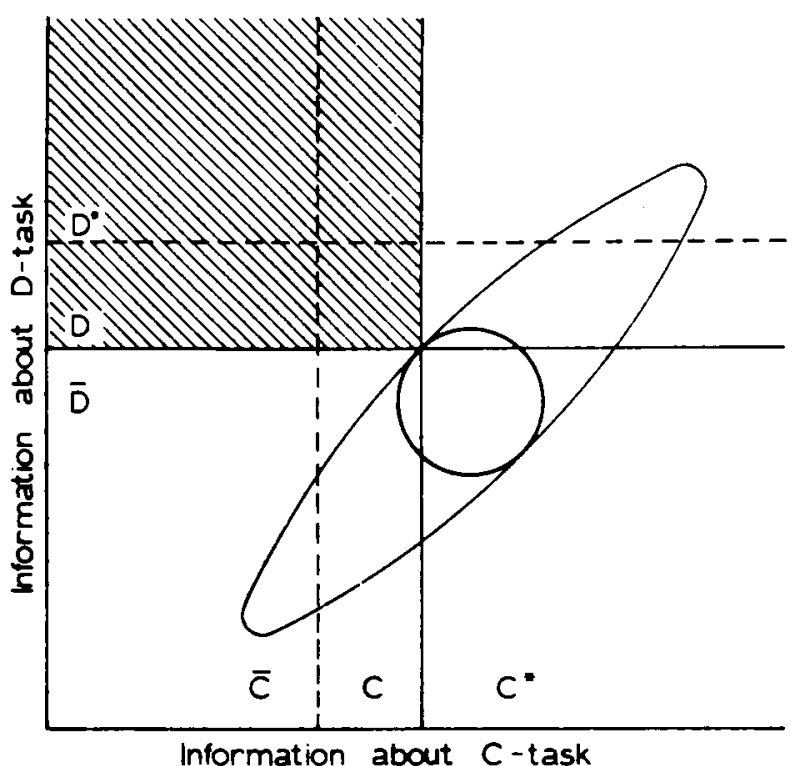

Fig. 1. Possible amounts of information relevant to each discrimination on each trial. Perceptual dependence occurs when no trials fall within the shaded area. Circle and oval represent possible limitations within an experiment.

subdivided into a number of substates of different degrees of partial information. The $\mathrm{S}$ may have access to these substates, if there are more than one, for the purpose of setting criteria for responses or confidence ratings. Thus, if the number of substates is infinite, and if States $\bar{C}, \bar{D} . C^{*}$, and $D^{*}$ never occur, the assumptions here are consistent with those of signal detection theory (Green \& Swets, 1966). On the other hand, if C and D cannot be subdivided, the present assumptions would be equivalent to those of Krantz's (1969) 3-LHT theory.

Figure 1 represents the amount of information relevant to each task that may be extracted on a given trial. More information is assumed to be monotonically related to a higher probability of being correct (not a higher probability of a particular response). If the information extracted about Task $\mathrm{C}$ falls below the amount represented by the vertical dashed line, i.e., to the left of it in Fig. 1, the $\mathrm{S}$ will be in State $\overline{\mathrm{C}}$. If the information falls between the dashed and vertical solid line to the right, the $S$ will be in State $C$ : right of the vertical solid line represents State $C^{*}$. Information about the $\mathrm{D}$ task is represented vertically.

The significance of perceptual dependence, in terms of the unrestrictive assumptions represented in Fig. 1, is simply that no trials may fall in the diagonal-striped area. That is, if there are any trials on which the $S$ is in State D or State D* while he is also in State $\bar{C}$ or State $C$, a result of perceptual dependence of Task D on Task $C$ will not be obtained, for the $\mathrm{S}$ will make errors on Task $\mathrm{C}$ on some of the trials in States $\bar{C}$ and $\mathrm{C}$, and, at the same time, will be more likely than chance to be correct on Task D. for he will be in State D or State D*.
Thus, the implication of a true finding of perceptual dependence is that State $D$ or State $D^{*}$ may occur only with $C^{*}$, and State $\bar{D}$ must occur with $\bar{C}$ or $C$.

A corollary of this conclusion is that States $\bar{D}$ and $C^{*}$ must occur. If $\bar{D}$ did not occur on any trials, the only quadrant remaining as a possibility would be that above and to the right of the two solid lines in Fig. 1. In this quadrant, however, only $\mathrm{C}^{*}$ is possible for Task $\mathrm{C}$, and no errors at all would be made on that task. Thus, a threshold state, $\overline{\mathrm{D}}$, must exist. Likewise, if $\mathrm{C}^{*}$ never occurred, all the trials would fall in the lower left quadrant formed by solid lines, and the $\mathrm{S}$ would not perform above chance on Task $D$, for he would always be guessing. In this case, performance on Task D would be limited by an external threshold; that is, the information provided would never be sufficient for an informed response.

\section{EXPERIMENT 1}

It seems reasonable that if an $S$ cannot see where a stimulus is, in the visual field, he can hardly be expected to be able to tell us much about its details. As a first attempt to show perceptual dependence, a pair of letters, each letter either an $\mathrm{X}$ or an $\mathrm{O}$, was presented either on the left or the right side of a cathode ray tube (CRT), tachistoscopically. The $S$ was required to decide whether the members of the pair were the same or different, and where the pair occurred.

\section{Method}

Stimuli were presented on a Tektronix 602 oscilloscope with a P-15 (fast decay) phosphor. Each trial began with a fixation point which appeared in the middle of the screen for $0.5 \mathrm{sec}$. A pair of letters was then presented either on the left or on the right side of the screen, chosen with equal probability from the possible combinations of letter pair and position. with the shortest distance between the fixation point and any part of the letters being $3 \mathrm{~cm}$. Each letter was $8 \mathrm{~mm}$ high and $5 \mathrm{~mm}$ wide. and was made up of $13(\mathrm{X})$ or $15(\mathrm{O})$ dots. The $S$ sat about $60 \mathrm{~cm}$ from the display. so the entire display subtended a visual angle of about 4 deg. A pair could be XX, XO. OX. or OO with equal probability. The pair of letters was presented for two complete plottings of all the dots, which took about $1 \mathrm{msec}$. Several milliseconds later. this duration being set for each session, a mask appeared for $0.5 \mathrm{sec}$. The mask was in the shape of a rectangle, $84 \mathrm{~mm}$ wide and $21 \mathrm{~mm}$ high, with its horizontal center coincident with the fixation point. which covered the letters no matter where they were presented. It was made up of dots plotted at random positions within the rectangle at a rate of approximately $20 \mathrm{dots} / \mathrm{msec}$. After the mask, the $S$ took as long as he wanted to respond by pressing one of four keys on a Teletype. The left two keys meant that the $S$ thought the stimulus was on the left side, and the right two keys. on the right side. The first and third key's meant that the $S$ thought that the letters in the pair were the same. the second and fourth, different. When the $\mathrm{S}$ responded, feedback was provided by plotting the original stimulus in its original position for $1 \mathrm{sec}$, with the fixation point on during this time. to be followed by the $0.5-\mathrm{sec}$ foreperiod of the next trial. There were 512 trials in each session. which usually took about $20 \mathrm{~min}$.

The delay of the mask was adjusted for each S. for each session, in an attempt to maintain a level of $83 \%$ correct on the 
position discrimination alone. This level was chosen in an attempt to strike a balance between the fact that shorter delay's would make both discriminations more difficult-in the extreme case leading to chance performance on both discriminations-while longer delays would make performance on the position discrimination so good that there would be too few trials on which the position discrimination was wrong. The particular level chosen would be statistically optimal if deviation from chance performance on one discrimination were directly proportional to deviation on the other. All Ss had had extensive experience with similar tasks involving recognition of letters, so it was possible to choose the delay time with some accuracy even for the first session. The delays used ranged from 6 to $28 \mathrm{msec}$.

Adjustment of delays for each session, rather than holding the delay constant. may be seen as a way of maintaining a constant level of difficulty in the face of improvement with practice. It may be claimed that a finding of perceptual dependence could result from this adjustment. That is, any delay long enough to allow the $\mathrm{D}$ task to rise above State $\overline{\mathrm{D}}$ would necessarily be long enough so that $\mathrm{C}^{*}$ always occurred, and errors on Task $\mathrm{C}$ would occur only when shorter durations were used. Three points can be made in answer to this objection: First. if it were true, the inferences made above about the existence of thresholds would apply to external thresholds. absolute requirements for information. rather than to internal thresholds or states of the S. Second. the same objection could be made if constant delay's were used. as practice could have the same effect as lengthening the delay: thus. the problem is ultimately inevitable. Third, the proportion of errors actually made on each task actually changed very little, and errors occurred for both tasks in every single session.

\section{Results}

Table 1 shows the results for each $\mathrm{S}$, and the proportions of correct responses on the same-different discrimination expressed separately according to correctness on the position discrimination. Overall, when the position discrimination was incorrect, performance on same-different did reach significance at the .05 level (binomial test). Thus, the same-different task was not strictly dependent upon the position task. However, all Ss except C.W. and C.K. performed at or close to the chance level on same-different when position was incorrect: C.W. was the only $\mathrm{S}$ to perform significantly above chance (.02 level). On the other hand. it is possible that some of the Ss (P.B. and A.S.) would not have performed above chance even if they had run for many more sessions. It may be of interest that Ss who performed well on the same-different task when wrong on position also performed relatively well when right on position. In fact, the rank order correlation across Ss between these two scores on the same-different task was significant at the .01 level (Kendall's tau).

\section{EXPERIMENT II}

Experiment I suggests that information about the form of a visual stimulus can be extracted even when information about its position is insufficient for a correct judgment. The present experiment is an attempt to confirm this general finding. for all Ss. by using an easier "form" discrimination than the same-different task used in Experiment I.
Table 1

Data for Experiment I Combined Over Sessions for Each S

\begin{tabular}{|c|c|c|c|c|}
\hline \multirow[b]{2}{*}{$S$} & \multirow[b]{2}{*}{ Position } & \multicolumn{2}{|c|}{ Same-Different } & \multirow{2}{*}{$\begin{array}{c}\text { Condi- } \\
\text { tional } \\
\text { Propor- } \\
\text { tion } \\
\text { Correct }\end{array}$} \\
\hline & & Incorrect & Correct & \\
\hline CK $(8)^{*}$ & $\begin{array}{l}\text { Incorrect } \\
\text { Correct }\end{array}$ & $\begin{array}{r}337 \\
1011\end{array}$ & $\begin{array}{r}368 \\
2380\end{array}$ & $\begin{array}{l}.522 \\
.702\end{array}$ \\
\hline AS (6) & $\begin{array}{l}\text { Incorrect } \\
\text { Correct }\end{array}$ & $\begin{array}{l}220 \\
840\end{array}$ & $\begin{array}{r}221 \\
1791\end{array}$ & $\begin{array}{l}.501 \\
.681\end{array}$ \\
\hline $\mathrm{CW}(6)$ & $\begin{array}{l}\text { Incorrect } \\
\text { Correct }\end{array}$ & $\begin{array}{l}116 \\
613\end{array}$ & $\begin{array}{r}153 \\
2190\end{array}$ & $\begin{array}{l}.569 \\
.781\end{array}$ \\
\hline$S G(6)$ & $\begin{array}{l}\text { Incorrect } \\
\text { Correct }\end{array}$ & $\begin{array}{l}151 \\
803\end{array}$ & $\begin{array}{r}168 \\
1950\end{array}$ & $\begin{array}{l}.527 \\
.708\end{array}$ \\
\hline PB (6) & $\begin{array}{l}\text { Incorrect } \\
\text { Correct }\end{array}$ & $\begin{array}{r}219 \\
1057\end{array}$ & $\begin{array}{r}216 \\
1580\end{array}$ & $\begin{array}{l}.497 \\
.599\end{array}$ \\
\hline $\operatorname{ISS}(4)$ & $\begin{array}{l}\text { Incorrect } \\
\text { Correct }\end{array}$ & $\begin{array}{r}91 \\
726\end{array}$ & $\begin{array}{r}93 \\
1138\end{array}$ & $\begin{array}{l}.505 \\
.611\end{array}$ \\
\hline Total & $\begin{array}{l}\text { Incorrect } \\
\text { Correct }\end{array}$ & $\begin{array}{l}1134 \\
5050\end{array}$ & $\begin{array}{r}1219 \\
11029\end{array}$ & $\begin{array}{l}.518 \\
.686\end{array}$ \\
\hline
\end{tabular}

*Number of sessions

\section{Method}

Instead of deciding whether the two letters were the same or different. both letters in the pair were always the same. that is, either $\mathrm{XX}$ or $\mathrm{OO}$. In addition to discriminating position. the $\mathrm{S}$ had to decide whether the $\mathrm{OO}$ or the $\mathrm{XX}$ had been presented, using the keys that were used in Experiment I for same and different. respectively. In addition (due to an inadvertant error. hopefully of no great consequence). immediately after the mask terminated. the $\mathrm{S}$ was presented with the four possible alternatives on the display: OO on the left in the position in which it would have occurred. XX directly beneath the OO. and then $O O$ and $X X$ on the right in positions below their counterparts on the left. (The order of stimuli. from the top down. corresponded to the order of the key's used for each stimulus.)

\section{Results}

Table 2 shows the results for this experiment. Quite clearly, in this experiment. Ss were discriminating the identity of the letters even when they were wrong on their position. All Ss except J.B.. who ran only one session, performed above chance on the identity task, even when incorrect on the position task, at least at the .005 level.

\section{EXPERIMENT III}

In Experiment III, several changes in procedure are made for the purpose of increasing the likelihood of fitting the data with a perceptual-dependence model. Most importantly. Ss were asked to report a more abstract property of the stimulus, the sound of a single letter when pronounced. in hopes that such information would not become available prior to information about location. 
Table 2

Data for Experiment II

\begin{tabular}{|c|c|c|c|c|}
\hline \multirow[b]{2}{*}{$S$} & \multirow[b]{2}{*}{ Position } & \multicolumn{2}{|c|}{$\mathrm{XX}$ vs 00} & \multirow{2}{*}{$\begin{array}{c}\text { Condi- } \\
\text { tional } \\
\text { Propor- } \\
\text { tion } \\
\text { Correct } \\
\end{array}$} \\
\hline & & Incorrect & Correct & \\
\hline JB $(1)^{*}$ & $\begin{array}{l}\text { Incorrect } \\
\text { Correct }\end{array}$ & $\begin{array}{r}39 \\
103\end{array}$ & $\begin{array}{r}49 \\
321\end{array}$ & $\begin{array}{l}.557 \\
.757\end{array}$ \\
\hline MS (6) & $\begin{array}{l}\text { Incorrect } \\
\text { Correct }\end{array}$ & $\begin{array}{l}122 \\
818\end{array}$ & $\begin{array}{r}171 \\
1961\end{array}$ & $\begin{array}{l}.584 \\
.706\end{array}$ \\
\hline SG (3) & $\begin{array}{l}\text { Incorrect } \\
\text { Correct }\end{array}$ & $\begin{array}{l}253 \\
170\end{array}$ & $\begin{array}{l}316 \\
797\end{array}$ & $\begin{array}{l}.555 \\
.824\end{array}$ \\
\hline AS (5) & $\begin{array}{l}\text { Incorrect } \\
\text { Correct }\end{array}$ & $\begin{array}{r}86 \\
348\end{array}$ & $\begin{array}{r}171 \\
1955\end{array}$ & $\begin{array}{l}.665 \\
.849\end{array}$ \\
\hline PB (4) & $\begin{array}{l}\text { Incorrect } \\
\text { Correct }\end{array}$ & $\begin{array}{l}144 \\
399\end{array}$ & $\begin{array}{r}209 \\
1296\end{array}$ & $\begin{array}{l}.592 \\
.765\end{array}$ \\
\hline
\end{tabular}

* Number of sessions

\section{Method}

Only one letter was presented on each trial, in a position corresponding to that of the left letter of the left pair or the right letter of the right pair in Experiments I and II. In addition to judging the position of the letter, as before, the $S$ had to say whether or not the letter rhymed with "E." (In Canada, there are eight such letters. B. C, D, E, G, P, T, and V.) Thus, the two discriminations were of position and sound. respectively. It was hypothesized that the sound discrimination would be dependent upon the position discrimination.

The nonrhyming letters. to which a "no" response was to be made, consisted of the remainder of the alphabet, excluding A and $W$. so as to make 16 letters not rhyming with $E$. Rhyming and nonrhyming stimuli were equally likely, and within each group. all the letters were equally likely. No feedback was given. Only Ss familiait with the letter set were used. Otherwise, the procedure was the same as in Experiment I.

\section{Results}

Table 3 shows the results for each S. All of the Ss' data were fil well by the perceptual-dependence model. None of the Ss deviated significantly from chance performance on the sound discrimination when the position discrimination was incorrect. The summed results across all Ss also did not differ significantly from chance. (A proportion as high as 0.519 would have exceeded chance at the .05 level, given the same number of position errors.)

To test the possibility that chance values resulted from above-chance performance on one side and below-chance on the other, values of chi squared (uncorrected for continuity) were computed separately for each side, and then added for each $\mathbf{S}$, for only those trials on which the position judgment was incorrect. The null hypothesis was that stimuli and responses were independent with respect to the sound judgment. These values, with $2 \mathrm{df}$ each, were $0.119,0.283,4.253,0.834$, and 0.155 for the five Ss, respectively, in the order of Table 3. Only the value for M.P. approached significance: the other values, and their sum (10 df) fell far short of significance. Thus, the hypothesis of pure guessing on these trials is a good approximation to the data.

On the other hand, all Ss did perform significantly above chance on the sound discrimination when the position discrimination was correct. The results of Experiment II make it unlikely that the present results are due to exclusive attention to one side at a time. Ss can make use of information from both sides at once.

\section{EXPERIMENT IV}

Experiment III may not be a convincing demonstration of dependence for several reasons. One reason is that the result may be coincidence. due to the small amount of data. Another is that the $S$ might have used information about the sound of the letter to help judge its position. For example, he might have taken a "sound reading" from each side and judged the letter to be on the side with the strongest reading. If the readings were ordered along a unidimensional continuum of "E-ness" (positive or negative), under certain circumstances, perceptual dependence could appear to hold, even though no threshold states existed. (I thank Saul Sternberg for pointing this out.) In Experiment IV, a kind of perceptual dependence is shown to fit data gathered in a very different situation, not subject to this particular alternative explanation. Thus, the case for dependence as a plausible model for some tasks is strengthened by accumulating additional data.

In Experiment IV, instead of judging the position of a stimulus. Ss were required to detect its presence or absence and to indicate their confidence. They also had to indicate whether they thought the stimulus, a pair of letters, was a word or not, even when they thought nothing had been presented. The perceptual-dependence model would predict that when a stimulus was presented

Table 3

Data for Experiment III

\begin{tabular}{|c|c|c|c|c|}
\hline \multirow[b]{2}{*}{$\mathrm{S}$} & \multirow[b]{2}{*}{ Position } & \multicolumn{2}{|c|}{ Rhyme With E? } & \multirow{2}{*}{$\begin{array}{l}\text { Condi- } \\
\text { tional } \\
\text { Propor- } \\
\text { tion } \\
\text { Correct }\end{array}$} \\
\hline & & Incorrect & Correct & \\
\hline SG $(4)^{*}$ & $\begin{array}{l}\text { Incorrect } \\
\text { Correct }\end{array}$ & $\begin{array}{l}293 \\
515\end{array}$ & $\begin{array}{l}286 \\
954\end{array}$ & $\begin{array}{l}.494 \\
.649\end{array}$ \\
\hline $\mathrm{JC}(4)$ & $\begin{array}{l}\text { Incorrect } \\
\text { Correct }\end{array}$ & $\begin{array}{l}322 \\
357\end{array}$ & $\begin{array}{r}317 \\
1052\end{array}$ & $\begin{array}{l}.496 \\
.747\end{array}$ \\
\hline MP (4t) & $\begin{array}{l}\text { Incorrect } \\
\text { Correct }\end{array}$ & $\begin{array}{l}217 \\
681\end{array}$ & $\begin{array}{r}199 \\
1522\end{array}$ & $\begin{array}{l}.478 \\
.691\end{array}$ \\
\hline JB (4) & $\begin{array}{l}\text { Incorrect } \\
\text { Correct }\end{array}$ & $\begin{array}{l}131 \\
762\end{array}$ & $\begin{array}{r}129 \\
1026\end{array}$ & $\begin{array}{l}.496 \\
.574\end{array}$ \\
\hline$C D(4)$ & $\begin{array}{l}\text { Incorrect } \\
\text { Correct }\end{array}$ & $\begin{array}{r}43 \\
606\end{array}$ & $\begin{array}{r}58 \\
1341\end{array}$ & $\begin{array}{l}.574 \\
.689\end{array}$ \\
\hline Total & $\begin{array}{l}\text { Incorrect } \\
\text { Correct }\end{array}$ & $\begin{array}{l}1006 \\
2921\end{array}$ & $\begin{array}{r}989 \\
4995\end{array}$ & $\begin{array}{l}.496 \\
.631\end{array}$ \\
\hline
\end{tabular}

* Vumber of sessions 
and when the $S$ guessed that nothing had been presented. he would be unable to tell whether the stimulus was a word or not. (For a different analysis of the same kind of experiment, see Shipley, 1960.)

\section{Method}

The sequence and timing of events on each trial was the same as in Experiment l. except that the fixation point was absent during the feedback. Letter pairs were presented in the position of the left stimuli in Experiments I and II. The mask occupied only the left half of its area in previous experiments. and was thus twice as dense. The "fixation" point occurred in a position corresponding to the lower left corner of the mask, during the foreperiod. Feedback was presented about $2 \mathrm{~cm}$ below the position of the stimulus, and consisted of the letter pair presented or of nothing when nothing was presented.

With equal probability; either a letter pair or nothing was presented on each trial. The letter pair could be either a common word (AT. OR. DO. BE. ME, NO, AM, or IF) or a nonword (AR, OT. DE, BO. MO. NE, AF : or IM), and it was chosen with equal probability from the 16 pairs. The $\mathrm{S}$ used eight keys of a Teletype to make his response. The $S$ was told to use his left hand (Keys 1-4) to indicate a judgment that a word had been presented and his right hand (Keys 5-8) to indicate a nonword, and he was encouraged to try to guess even if he didn't see anv thing. Within each hand, he was instructed to use the left two fingers $(1$ and 2,5 and 6 ) to indicate a judgment that no stimulus had been presented, with 1 and 5 indicating a high degree of confidence. Keys 3 and 7 were to indicate a judgment that a pair might have been presented, and 4 and 8 . a confident judgment that a pair had been presented. Henceforth, we shall speak of responses considered across both hands as Categories 1. 2. 3. and 4, from left to right. respectively. The Ss were shown the list of words and nonwords before each session. Delays of the mask were set on the basis of previous experiments for each $\mathrm{S}$. and were decreased by 1 or $2 \mathrm{msec}$ each session if too few misses were being made. Ss were encouraged to use the same criteria for the four detection-response categories from session to session. regardless of the small variations in difficulty that may have occurred.

All Ss were run for six sessions except for D.D. and A.A.D.D. was run for an additional two sessions in order to check his results (described below). All qualitative statements about results hold just as well if his last two sessions are ignored. A.A. did not appear for her scheduled appointments for over a week, at which time the experiment had to be terminated.

\section{Results}

Table 4 shows the number of responses made by each $S$ in each detection-response category, the posterior probabilities of the signal, and the probabilities of a correct recognition response, when a stimulus was presented, of course. The probability of correct recognition was calculated by taking the average of two values. the probability correct when the stimulus was a word, and the probability correct when it was not. This procedure insured that low values could not result spuriously from response biases and differences in detectability of words and nonwords.

For Category 1. recognition probability did not exceed the chance level of 0.5 for any $S s$ or for the combined results $\left(\chi^{2}=0.019\right.$. $\left.\mathrm{df}=1\right)$ : that is. stimuli and responses were independent.
Table 4

Data for Experiment IV

\begin{tabular}{|c|c|c|c|c|c|}
\hline \multirow[b]{2}{*}{$\mathrm{S}$} & & \multicolumn{4}{|c|}{$\begin{array}{c}\text { Detection } \\
\text { Response Category }\end{array}$} \\
\hline & & 1 & 2 & 3 & 4 \\
\hline $\mathrm{DD}$ & $\begin{array}{l}\text { Stimulus } \\
\text { No Stimulus } \\
\text { p (Stimulus/Response) } \\
\text { p (Recognition)* }\end{array}$ & $\begin{array}{r}263 \\
1534 \\
.146 \\
.448\end{array}$ & $\begin{array}{l}315 \\
257 \\
.551 \\
.486\end{array}$ & $\begin{array}{l}506 \\
232 \\
.686 \\
.566\end{array}$ & $\begin{array}{r}945 \\
44 \\
.956 \\
.741\end{array}$ \\
\hline $\mathrm{CL}$ & $\begin{array}{l}\text { Stimulus } \\
\text { No Stimulus } \\
\text { p (Stimulus/Response) } \\
\text { p (Recognition) }\end{array}$ & $\begin{array}{l}149 \\
400 \\
.271 \\
.478\end{array}$ & $\begin{array}{r}96 \\
260 \\
.270 \\
.584\end{array}$ & $\begin{array}{l}229 \\
439 \\
.343 \\
.514\end{array}$ & $\begin{array}{r}1058 \\
441 \\
.706 \\
.591\end{array}$ \\
\hline HL & $\begin{array}{l}\text { Stimulus } \\
\text { No Stimulus } \\
\text { p (Stimulus/Response) } \\
\text { p (Recognition) }\end{array}$ & $\begin{array}{r}450 \\
1200 \\
.273 \\
.491\end{array}$ & $\begin{array}{r}4 \\
3 \\
.571 \\
.500\end{array}$ & $\begin{array}{r}77 \\
54 \\
.588 \\
.491\end{array}$ & $\begin{array}{r}1015 \\
269 \\
.790 \\
.634\end{array}$ \\
\hline IV & $\begin{array}{l}\text { Stimulus } \\
\text { No Stimulus } \\
\text { p (Stimulus/Response) } \\
\text { p (Recognition) }\end{array}$ & $\begin{array}{l}121 \\
633 \\
.160 \\
.489\end{array}$ & $\begin{array}{r}48 \\
174 \\
.216 \\
.545\end{array}$ & $\begin{array}{l}317 \\
428 \\
.426 \\
.523\end{array}$ & $\begin{array}{r}1075 \\
276 \\
.796 \\
.557\end{array}$ \\
\hline WP & $\begin{array}{l}\text { Stimulus } \\
\text { No Stimulus } \\
\text { p (Stimulus/Response) } \\
\text { p (Recognition) }\end{array}$ & $\begin{array}{l}233 \\
782 \\
.230 \\
.530\end{array}$ & $\begin{array}{l}120 \\
447 \\
.212 \\
.553\end{array}$ & $\begin{array}{l}301 \\
145 \\
.675 \\
533\end{array}$ & $\begin{array}{l}901 \\
143 \\
.863 \\
.635\end{array}$ \\
\hline ST & $\begin{array}{l}\text { Stimulus } \\
\text { No Stimulus } \\
\text { p (Stimulus/Response) } \\
\text { p (Recognition) }\end{array}$ & $\begin{array}{l}112 \\
300 \\
.272 \\
.547\end{array}$ & $\begin{array}{l}291 \\
659 \\
.306 \\
.516\end{array}$ & $\begin{array}{l}746 \\
563 \\
.570 \\
.527\end{array}$ & $\begin{array}{r}363 \\
38 \\
.905 \\
.716\end{array}$ \\
\hline WR & $\begin{array}{l}\text { Stimulus } \\
\text { No Stimulus } \\
\text { p (Stimulus/Response) } \\
\text { p (Recognition) }\end{array}$ & $\begin{array}{l}107 \\
650 \\
.141 \\
.551\end{array}$ & $\begin{array}{r}96 \\
306 \\
.239 \\
.613\end{array}$ & $\begin{array}{l}411 \\
467 \\
.468 \\
.526\end{array}$ & $\begin{array}{r}948 \\
87 \\
.916 \\
.734\end{array}$ \\
\hline $\mathbf{A A}$ & $\begin{array}{l}\text { Stimulus } \\
\text { No Stimulus } \\
\text { p (Stimulus/Response) } \\
\text { p (Recognition) }\end{array}$ & $\begin{array}{l}185 \\
923 \\
.167 \\
.512\end{array}$ & $\begin{array}{r}41 \\
47 \\
.466 \\
.685\end{array}$ & $\begin{array}{r}257 \\
47 \\
.845 \\
.642\end{array}$ & $\begin{array}{r}535 \\
13 \\
.976 \\
.761\end{array}$ \\
\hline $\begin{array}{l}\text { Com- } \\
\text { bined } \\
\text { Across } \\
\text { Ss }\end{array}$ & $\begin{array}{l}\text { Stimulus } \\
\text { No Stimulus } \\
\text { p (Stimulus/Response) } \\
\text { p (Recognition) }\end{array}$ & $\begin{array}{l}1620 \\
6422 \\
.201 \\
.502\end{array}$ & $\begin{array}{r}1011 \\
2153 \\
.320 \\
.534\end{array}$ & $\begin{array}{r}2844 \\
2375 \\
.545 \\
.546\end{array}$ & $\begin{array}{l}6840 \\
1311 \\
.839 \\
.659\end{array}$ \\
\hline
\end{tabular}

*These values are based on the number of trials in the top row for each $S$. It should be noted that some of these numbers are small.

For Category 2, the combined results did exceed chance $\left(\chi^{2}=4.42, \mathrm{df}=1, \mathrm{p}<.05\right)$, but this appears to be due to W.R. and A.A. These Ss may have used Category 2 on some trials on which they were in State $C^{*}$ with respect to the detection task, allowing them to perform above chance on Task $D$, the recognition task. That is, they may have disobeyed the instruction to use Categories 1 and 2 only when they thought no stimulus was presented. Alternatively, entry into State $\mathrm{C}$ may have been sufficient for entry into State D, and these Ss may have used Category 2 for State $\mathrm{C}$ and Category 1 for State $\overline{\mathrm{C}}$. Thus, the present procedure is inconclusive with respect to the existence of State $C^{*}$. Its results bear only on the issue of the existence of State $\overline{\mathrm{D}}$, which seems to characterize the use of Category 1. 
The results for recognition given Category 1 responses were unlikely to be due to extreme response biases. All Ss except W.P. used both responses, word and nonword, in Category 1 in every session. For other Ss, the probability of responding "word" ranged from 0.3 to 0.5 and was approximately constant from session to session.

Thus, the results of Experiment IV are consistent with the assumption of an internal threshold for the recognition task, a threshold never exçeeded when Category 1 is used. Whether perceptual dependence holds as well cannot be decided, as the existence of State $\mathrm{C}^{*}$ for the detection task remains in doubt.

The results of D.D. are worthy of special comment. For both categories, 1 and 2, recognition did not exceed chance probability. Yet, the posterior probability of a signal increased from 0.146 for Category 1 to 0.551 for Category 2. Thus, while the use of Category 2 transmitted considerable information about the presence of the stimulus, no information was transmitted about its identity. For this $S$, at least, it seems possible to enter a state of considerable information about Task $C$ while remaining in State $\bar{D}$ with respect to Task $D$.

\section{DISCUSSION}

While the perceptual-dependence model adequately describes the results of Experiments III and IV, alternative models surely exist which make predictions indistinguishable from the dependence model on the basis of the small amount of available data. For example, there may be a bivariate signal-detection-theoretic (Green \& Swets, 1966) model, with some distributions of strengths, that would fit the data as well as the dependence model. Or the demand characteristics of the experiment may induce the S not to "try" on Task D when he guesses on Task $\mathrm{C}$ (although one might wonder why this didn't happen in Experiment II). In fact, there are so many such alternatives that it seems futile to try to reject them all. Instead, it will be argued that the perceptual-dependence model merits consideration because it can be explained in a way which also can account for a number of other results as well, a hypothesis of successive stages with thresholds. (A second explanation of perceptual dependence will be described below.)

The hypothesis of interest assumes that the two discriminations are mediated by successive processing stages. The second stage takes as its input the output of the first. This hypothesis includes another assumption, which we shall call the complete-information assumption. According to this assumption, the level of information on Task D (as illustrated in Fig. 1) cannot begin to rise above its prestimulation level until State $C^{*}$ has been reached by the first stage; and after that point, the course of the increase of second-stage information is unaffected by any further increases or decreases in first-stage information level. In Experiment III, for example, the output of the first stage might consist of a specification of location. The second stage might then focus its analytic mechanisms on the location in question.

A consequence of the complete-information assumption concerns the effects of experimental manipulations on reaction time for a judgment that involves both stages. Sternberg (1969) has described a number of situations in which two different manipulations have additive effects on reaction time, in cases in which it can reasonably be assumed that the manipulations could affect different processing stages. Presumably, each manipulation affects the time taken by one stage only, so that applying both manipulations together increases reaction time by an amount equal to the sum of the increases resulting from each manipulation applied alone. Such additive effects are entirely consistent with the complete-information assumption, since the second stage is triggered by completion of the first and proceeds independently thereafter; the duration of the second will not be directly affected by the duration of the first. This assumption corresponds to Sternberg's (1969) assumption that the output of a stage is invariant with factors influencing its duration, insofar as that output serves as the effective input to the next stage.

It should be noted that the assumption of successive stages per se, without the complete-information assumption, necessitates neither factor additivity nor perceptual dependence. If the information relevant to the decision made by the second stage can begin to increase even when only partial information is available from the first, it is easy to find sets of assumptions which violate both factor additivity and perceptual dependence (for example, those of the sort made by Levinson, 1968). Furthermore, factor additivity and perceptual dependence may not be the only sorts of empirical results useful for discovering processing stages. For example, we may infer that Stage B follows Stage A in sequence if we can find different tasks using the respective outputs of each stage, and if every factor which affects the Stage A task also affects the Stage B task, although some factors affect the latter but not the former.

The main point of the present proposal thus concerns the complete-information assumption and not the idea of successive stages per se. Both perceptual-dependence and additive-factor results may be explained by a simple model of successive stages with this complete-information assumption. If both of these kinds of results continue to turn up with ease and regularity, our analysis would suggest that thresholds provide the normal mechanism for the passage of information between stages. In essence, we are suggesting that much of human information processing is "digital" rather than "analog." This suggestion may be made more plausible by showing that neural mechanisms exist in the central nervous system which might account for the internal 
thresholds which are proposed.

While the explanation of perceptual dependence in terms of successive stages may appear to be the most interesting. there is a second explanation worthy of consideration for its simplicity. Like the successive-stage hypothesis, this second hypothesis does not depend on any notion of statistical coincidence or indistinguishability. It also requires the assumption of an internal threshold.

The essential assumption of this second hypothesis is that more information is required for a given level of performance on the dependent task, Task D (Fig. 1), than on the other task, Task $\mathrm{C}$. With the assumption of States $\bar{D}$ and $C^{*}$, perceptual dependence could result. for example, if all trials fell within the small circle in Fig. 1.

Dependence would be even more apparent if there were a correlation between the amounts of information extracted relevant to the two tasks, respectively. Then the trials could all fall within something like the large oval in Fig. 1, and there could be both a relatively high proportion of correct responses on Task D and a relatively high proportion of incorrect responses on Task C. Such a correlation could result from spontaneous fluctuations in arousal or attention to both tasks. It could also arise from extraction of basic units. or features, which provide information relevant to both tasks. While some features may provide more information relevant to one task or the other, correlation would result from the common variance attributable to the total number of features extracted on each trial.

According to this second hypothesis, the function of Task $C$ is simply to select those trials in which very little information is extracted relevant to either discrimination. Findings of perceptual dependence would thus be more likely when performance on Task C is much better than that on Task D, since errors on Task $C$ would then occur only if very little information relevant to Task $D$ were extracted. In the extreme case. if States $\bar{C}$ and $D^{*}$ could occur as well as States $\bar{D}$ and $\mathrm{C}^{*}$, it ought to be possible to reverse the direction of dependence by reversing the relative difficulty of the two tasks. This possibility could not occur if the assumption of successive stages were made.

The second hypothesis, that perceptual dependence results from a high threshold for Task $D$, provides a plausible account of the findings of Experiment I. Perceptual dependence occurred, if at all, only in those Ss who did relatively poorly on Task D, the same-different discrimination, overall. Thus, when these Ss were wrong on Task C, they were more likely than other $S s$ to be in State $\bar{D}$. It was as if the oval containing their trials (Fig. 1) were shifted downward relative to the other Ss. Further, Experiment II may be seen (among other possible interpretations) as a way of making easier the "dependent" discrimination of Experiment I, and thus causing apparent dependence to disappear for all Ss by moving the oval (Fig. 1) upwards into the striped region.

In conclusion, both simple explanations of perceptual dependence rely heavily on the idea of an internal threshold. This notion had been tentatively rejected for simple sensory tasks (Green \& Swets, 1966). But results from the experiments reported here, as well as results from other kinds of experiments, suggest that the idea is worthy of reexamination, at least in the context of more "cognitive" discrimination.

\section{REFERENCES}

Gamer, II. R., \& Morton. J. Perceptual independence: Definitions. models. and experimental paradigms. Psychological Bulletin. 1969. 72, 233-259.

Green. D. M.. \& Swets. J. A. Signal detection theor and psychophysics. New York: Wiley, 1966.

Krantz. D. H. Threshold theories of signal detection. Psychological Review. 1969. 76, 308-324.

Krantz. D. H.. \& Brumer. S. Information about the absence of signals: A test of threshold theory. Psychonomic Society. Twelfth Annual Meeting. St. Louis. 1972.

Levinson. J. F. Flicker fusion phenomena. Science, 1968. 160. 21-28.

Shipley. E. F. A model for detection and recognition with signal uncertainty. Psychometrika, 1960. 25. 273-289.

Sternberg. S. The discovery of processing stages: Extensions of Donders' method. Acta Psy chologica. 1969. 30. 276-315.

(Received for publication September 11. 1972; revision accepted January 31. 1973.) 